\title{
IPv6 + MOBILE-IP + MRSVP $=$ Internet Cellular Phone?
}

\author{
B. R. Badrinath and Anup K. Talukdar \\ Department of Computer Science, Rutgers University \\ New Brunswick, NJ 08903, USA \\ Telephone : 908-445-2082, Fax : 908-445-0537 \\ e-mail : $\{$ badri@cs, talukdar@paul\}.rugers.edu
}

\begin{abstract}
Initially, Internet protocols were not designed for mobility nor were they designed for handling real-time services. Recent research efforts on Mobile-IP and RSVP are aimed at providing these features in the Internet. However, additional support is needed to provide real-time services for moving users. One such real-time service for mobile users is the concept of an Internet Cellular Phone. An IP based backbone network capable of delivering packetized voice to moving users.
\end{abstract}

\section{Keywords}

Internet Cellular Phone, Mobility, Service Classes, Reservation Protocol

\section{INTRODUCTION}

This position paper argues for an architecture to support an Internet Cellular Phone network, a network that consists of an Internet backbone supporting a cellular phone network at the edge as shown in Figure 1. The edge network consists of base stations supporting IP cell phones or devices that can send and receive packetized voice and the backbone is the Internet. The base stations are connected to routers that support Mobile-IP routing (Perkins et al. 1996) and reservation protocols to guarantee service quality to moving users.

Why an Internet cellular phone? Here's why? We believe that determining the support protocols needed in the Internet to provide real-time service guarantees to moving users is a significant research problem. Also, the problem of mapping existing cellular services as IP services is an interesting research issue. For example, the problem of providing a cellular conference call using Mobile IP Multicast(Acharya et al. 1996). Providing integrated services in the Internet to moving users allows additional capabilities: simultaneously receiving e-mail while talking on the Internet Cellular Phone using the same network.

Recent research efforts in Mobile-IP are aimed at supporting mobility in the 


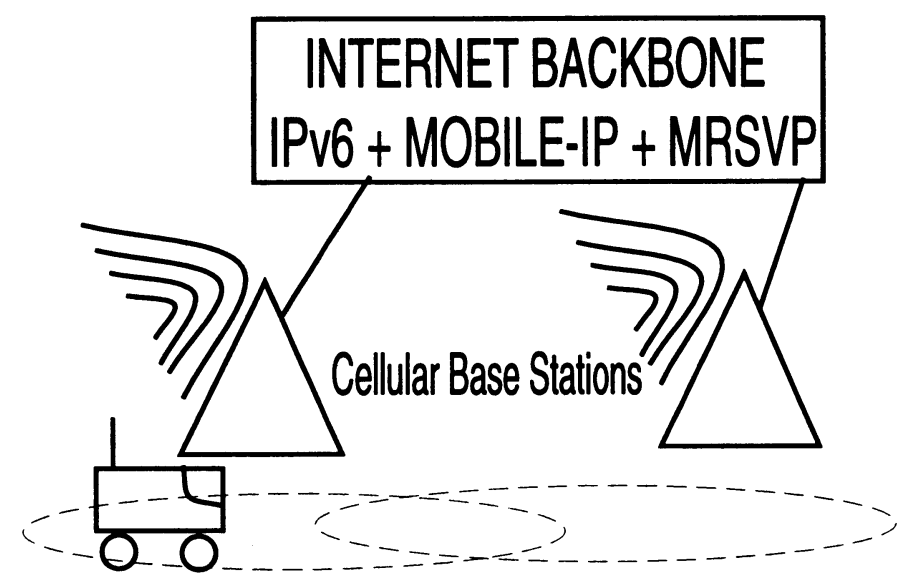

Figure 1 Architecture for an Internet Cellular Phone Network

Internet. Efforts in IPv6(Deering et al. 1995), RSVP(Zhang et al. 1993) and Integrated Services(Clark et al. 1992) are aimed at providing quality of service support in the Internet. However, due to the significant impact of mobility, providing real-time services to mobile users requires new service architecture and new protocols.

\section{MOTIVATION}

When a mobile host moves from one location to another with an open connection, the data flow path changes. As a result, the packet propagation time and the congestion delay along the new path may be different or the new cell may be so congested that the minimum QoS requirements of all users cannot be satisfied (Acampora et al. 1994, Lee 1995, Lu et al. 1996, Levine 1995). Due to handoff, additional delays and packet loss may occur (Caceres et al. 1996).

In the fixed network, several classes of service, e.g. guaranteed, predictive (Clark et al. 1992) and controlled-load(Wroclawski 1996), have been defined for real-time services. However, these service classes do not take into consideration the effects of mobility. There are two ways to provide QoS guarantees to mobile users. The first one is mobility independent, where a mobile user gets a QoS guarantee which is not affected by the mobility of the hosts. The second one is mobility dependent, where the QoS received by a mobile user may vary due to mobility of the hosts. To provide mobility independent service, it is necessary to make spatial resource reservations; i.e., reservations at all cells where the host may visit in the duration of the connection. 


\section{ISSUES}

Based on the above observations, a network system architecture for providing real-time services to mobile users has been proposed in (Talukdar et al. 1997). This architecture describes the service classes, admission control schemes, a reservation protocol, MRSVP, which is an extension of RSVP to handle mobile users, and the handoff management schemes. In this architecture, there are two service classes, mobility independent and mobility dependent. To obtain mobility independent service, a subscriber specifies its mobility specification, the set of cells it may visit during the lifetime of the connection, to the network. The network reserves resources from the sender to all cells of the mobility specification. However, the data flow starts only to the current location of the mobile host. The reservation along the path from the sender to the current cell over which data is flowing is called active reservation, whereas the reservation along the paths to the other cells over which data is not currently flowing is called passive reservation. Subscribers to the mobility dependent service class makes reservation from the sender only to their current cell. To improve network utilization, the admission control scheme allows the resources of passive reservation to be used by the users of mobility dependent service class; however, when the actual reservers of those resources arrive into that cell, they may suffer degradation in QoS.

In the rest of this section we identify the main issues in supporting an Internet cellular phone system on the framework of the above architecture. These are as follows:

- Service commitments: We have defined two types of service contracts: mobility independent and mobility dependent. Defining other types of service contracts that can be met in spite of mobility is an open research area.

- Mobility specification: It has been observed that, the movements of users have a regular component and a random component. Using these observations, there has been some proposals for predictive mobility management(Liu et al. 1996). We believe that short-term mobility prediction for the duration of a call can be done using these techniques and further research is required in integrating mobility specification with spatial resource reservations.

- Handoff management: The main approaches to reduce disruption during handoff are, multicasting the flow to neighboring cells of a mobile host, extending the routes from the current cell to the next cell, anticipatory handoff to the next predicted cell and using retransmission buffers to recover from packet losses due to handoff (Caceres et al. 1996, Keeton et al. 1995). Handoff interacts with reallocation of resources, degradation of service and resource reservations.

- Protocol integration: IPv6 (Deering et al. 1995) contains some unique features that provide some useful facilities to route data packets to mobile hosts efficiently(Perkins et al. 1996). In addition to features already present in RSVP, MRSVP protocol(Talukdar et al. 1997) requires several additional fea- 
tures; e.g., active and passive reservation, reservation by proxy agents to make spatial reservations for the different classes of services to mobile users.

Acknowledgements This research work was supported in part by DARPA under contract number DAAH04-95-1-0596, NSF grant numbers CCR 9509620, IRIS 95-09816.

\section{REFERENCES}

Acampora, A. S. and Naghshineh, M., An Architecture and methodology for Mobile-Executed Handoff in Cellular ATM Networks., IEEE JSAC, Vol 12, No. 8, October 1994.

Acharya, A., Bakre, A. and Badrinath, B. R., IP Multicast extensions for mobile internetworking, In IEEE Infocom'96, March 1996, pp. 67-74.

Clark, D. D., Shenker, S. and Zhang, L., Supporting Real-Time Applications In An Integrated Services Packet Network : Architecture and Mechanism., Proc. SIGCOMM '92, 1992.

Caceres, R. and Padmanabhan, V. N., Fast and Scalable handoffs for Wireless Internetworks, In Proc. ACM MobiCom '96, November 1996.

Deering, S. E. and Hinden, R. M., Internet Protocol version 6 (IPv6) specification. Internet RFC 1883, December 1995.

Keeton, K., Mah, B., Seshan, S., Katz, R. and Ferrari, D., Providing Connection-Oriented Network Services to Mobile Hosts, In Proc. of the 1st Usenix symposium on mobile and location independent computing, August 1995

Lee, K., Adaptive Network Support for Mobile Multimedia, In Proc. ACM MobiCom '95, pp. 62-74, November 1995.

Levine, D. A., Akyldiz, I. F. and Naghshineh, M., The Shadow Cluster Concept for Resource Allocation and Call Admission in ATM-Based Wireless Networks, In Proc. ACM MobiCom '95, pp. 62-74, November 1995.

Liu, G. and Maguire Jr., G., A class of mobile motion prediction algorithms for wireless mobile computing and communications, In ACM International Journal of Wireless Networks, 1996.

Lu. S. and Bharghavan, V., Adaptive Resource Management Algorithms for Indoor Mobile Computing Environments, Proc. SIGCOMM'96, August 1996.

Perkins, C. and Johnson, D. B., Mobility Support in IPv6, In Proc. ACM MobiCom '96, November 1996.

Talukdar, A. K., Badrinath, B. R. and Acharya, A., On Accommodating Mobile Hosts in an Integrated Services Packet Network, In the Proceedings of the IEEE INFOCOM'97, April 1997, pp. 1048-1055.

Wroclawski, J., Specification of the Controlled-Load Network Element Service. Internet-Draft, Work in progress, July 1996.

Zhang, L., Deering, S., Estrin, D., Shenker. S. and Zappala . D., RSVP: A New Resource ReSerVation Protocol. IEEE Network Sept. 1993. 